\title{
Breaking Barriers Through Edmodo: A Qualitative Approach on the Perceptions of University of Malaya Undergraduates
}

\author{
Farha Alia Mokhtar \\ Universiti Malaysia Terengganu
}

\begin{abstract}
With the advancement of digital technology, software and applications are overwhelmingly accessible to teachers and students. Digital designs for teaching and learning are highly encouraged by scholars as they prepare students of today for the demands of the future workforce. Thus, many educators use available social networks for their classrooms. However, the use of social networks in education presents disadvantages, as their invention is geared toward social networking purposes. Therefore, it's important to ask whether social learning platforms, such as Edmodo, provide a better alternative. The research aims to elucidate strategies for and advantages of executing Edmodo in education. The research employs purposive sampling, which led to sample of a total of four undergraduates from a prestigious Malaysian university. The research frameworks are on the theories of constructivism, hermeneutics, symbolic interactionism, and interpretivism, which focus on the process of meaning making and one's interpretation of a phenomenon. It aims to generate insights and sharing through in-depth interviews using interview protocol, photographs, and concept maps. The study executes open coding to identify emerging themes; axial coding, which focuses on finding the themes' consistency; and selective coding, whereby core categories are selected in order to illuminate Edmodo's effects. The findings are presented in a narrative manner. The pedagogical implications pertain to how Edmodo breaks barriers by enabling students to access learning resources beyond the classroom and empowering student-centered learning through novelty of tasks, suitable learning environment, and mobility.
\end{abstract}

Keywords: Edmodo, education, online learning, social learning platform, teaching and learning strategy

Mokhtar, F.A. (2018). Breaking barriers through Edmodo: A qualitative approach on the perceptions of University of Malaya undergraduates. Online Learning, 22(1), 61-80. doi:10.24059/olj.v22i1.1026 


\section{Breaking Barriers Through Edmodo: A Qualitative Approach on the Perceptions of University of Malaya Undergraduates}

Teaching millennials calls for a change in educational approach from a conventional to a more comprehensive, communicative, and technological one. Educators move forward day by day to ensure they have the best pedagogies and teaching methods that involve more social context in learning (Woo \& Reeves, 2007). Consequently, technology has been progressing rapidly to aid in the learning process (Stracker, 2011). In this paper, four undergraduates' journeys in exploring Edmodo while doing tasks on the site are presented. The objective is neither to model expert teaching nor to teach any specific subject but to discover thoughts and opinions that the participants have constructed, which will lead to understanding how this tool can be used and by what means it is beneficial in online learning.

Further, a survey conducted in 2013 revealed that $96 \%$ of students admitted using Internet access for social networking strategies, and $50 \%$ of discussions on social online platforms are schoolwork related (Rivero, 2013). These figures illustrate that students are usually online using social platforms while discussing assignments with peers via the same providers. For example, Facebook is used by students to stay in touch with classmates, resulting in students becoming more intimate and friendly with one another (Tidwell \& Walther, 2002). As teachers also use Facebook as a medium for conducting lessons and interacting with students, they disclose more information about themselves and seem approachable, which leads to higher levels of anticipated motivation, affective learning, and a comfortable classroom climate (Mazer, Murphy, \& Simonds, 2007). Despite these positive claims, Facebook does not help in setting boundaries between professional and personal matters, such as the appropriateness of the amount of shared information by teachers and the balance between academic discussion and social media activities on the site.

Besides Facebook, Twitter is also a social platform, where users "tweet," or post statuses with a maximum of 280 characters (Sulleyman, 2017). Other users are able to view, "retweet," comment, or "favorite" the tweet posted. Shachter (2011) proposes Twitter as an opportunity for learners to engage with peers outside of the classroom and to share personal thoughts about lessons learned. However, the evident weaknesses of Twitter in education are its character count limitations and buttons that are designed for social media purposes. On the other hand, a school in Birmingham used Skype as a teleconferencing tool to communicate with partners from Indiana and Columbia. A newspaper article entitled Kid to Kid Connection (2011) covered the story, stating that students made friends beyond their comfort zones and achieved learning outcomes. While Skype is a freemium instant messaging, video, and voice communication platform where basic services are free of charge while more advanced features must be paid for and can be downloaded on laptop or smartphone, it poses limitations as well owing to quality issues when the number of participants in a meeting or conference exceeds 25 (Moore, 2017). Another hindrance is the lack of collaborative instructional strategies, which resulted in lengthening the learning process for teacher and students (Beldarrain, 2006). Besides these limitations, educational institutions are struggling with issues pertaining to the privacy and security of educators and students on the social networks (Electronic Education Report, 2014). As a result, many schools block social networking sites due to the lack of adequate control and monitoring mechanisms (Rivero, 2013). The situations above prompted this study to look into Edmodo, a social learning platform, in order to determine its potential to become an alternative to the aforementioned social networks. 


\section{Review of Related Literature}

Edmodo was launched in 2008 as escapism to issues such as professional versus private, security, functional buttons, and others because the aforementioned issues became hindrances in online learning, particularly in social networking platforms. In addition, Edmodo simultaneously implements a "bottom-up" approach by targeting individual educators to use the application rather than getting entire educational institutions to sign up (Geron, 2011). This grants educators the liberty to choose instead of forcing them into using an unfamiliar social learning platform. Edmodo (2018) further illuminates its main aim on their website as follows:

Edmodo is a global education network that helps connect all learners with the people and resources needed to reach their full potential.

Since its inception in 2008, Edmodo has been housing millions of users worldwide, comprised of teachers, students, and parents. As of March 2016, over 63 million users have been actively working together in regard to academic affairs (Edmodo, 2016). Edmodo was designed to protect the privacy and security of students and teachers by providing a closed, private platform in which they can collaborate, share content, and leverage educational apps to augment in-classroom learning (Business Wire, 2014). Edmodo also organizes an online global educator conference known as EdmodoCon that attracts more than thirty thousand virtual attendees annually (Business Wire, 2014). The conference caters to idea sharing and collaboration among some of the world's most creative educators. Moreover, EdmodoCon is a free, live-streamed 11-hour event highlighting innovative educators who wish to showcase various ways to employ Edmodo with other digital tools in classrooms. Additionally, Dalsgaard (2008) claims that the integral point of a social network is the mixture of personalization and socialization; with Dalsgaard's notion in mind, it can be argued that the greatest innovation of online learning is when a social network is blended into education; therefore, Edmodo has been deemed one of the best platforms for social networking and academic affairs (Akbar, Purwarianti, \& Zubir, 2013).

In addition, Edmodo is user-friendly and easy to navigate and has multiple useful functions for learning purposes, including Reading, Assignments, and Paper-Studying (Tomassini, 2013). Edmodo as a social networking site can be incorporated into the curriculum and within teachers' locus of control (Anbe, 2013). Further, students who participated in a study related to Edmodo showcased fours skills while using the platform - namely, remembering, applying, evaluating, and creating (McClain \& Brown, 2013). Another advantage of Edmodo is the leniency for students to be mobile while participating in a class's online discussions (Chandler \& Redman, 2013). Edmodo is revealed to be a portal that has modest features, an intuitive interface, and media richness, and does not need hosting or a server (Thien et al., 2013).

As educators are urged to seek suitable digital designs for teaching and learning strategies due to the advent of technology (Stracker, 2011), it may evoke a keen interest in Edmodo as a medium for engaging students. Moreover, supplementing face-to-face instruction with webbased activities will increase interaction and creativity among students and subsequently increase student interest and self-learning (Amrein-Beardsley, Foulger, \& Toth, 2007; Vernadakis, 2012). Additionally, UNESCO (2004) urges students to concentrate on the significance of lifelong learning; to continuously upgrade knowledge and skills, to think critically, and to take initiative so as to adapt to global change. Therefore, this paper seeks to explore Edmodo's functions that support making education accessible to students, due to the need for 21 st-century learners to stay updated and relevant, which calls for incorporation of digital designs in education. 


\section{Purpose of Study}

This paper aims to do the following:

1. Illuminate Edmodo's potential to help students enhance their learning curve.

2. Find ways Edmodo may assist students in improving their learning experience.

\section{Methods}

This study stems from curiosity about discovering alternatives to social networking applications, as the use of social networks poses limitations in educational settings. Therefore, Edmodo was chosen as the tool for the study due to the advantages claimed by its developers and educators (Edmodo, 2014; Akbar et al., 2013; Hung \& Khine, 2006). The research focuses on perceptions of undergraduates from a Faculty of Education at a prestigious local university concerning the potential of Edmodo in educational environments.

\section{Research Model}

Constructivism, as defined by Crotty (1998), states that meaning is not discovered but constructed and that people derive meanings differently despite being exposed to the same phenomenon. In this sense, participants were encouraged to construct personal perceptions regarding Edmodo without any prior expectations or predetermined views. Meanwhile, hermeneutics is participative and cannot be produced by the researcher (Crotty, 1998). Hermeneutics is one of the theoretical backgrounds that permit participants to project their own thoughts on Edmodo through their work, comments, and encounters on the platform, which are gathered later for analysis. Symbolic interactionism, on the other hand, focuses on interpretations of environments through actions (Crotty, 1998), which allows the researcher to observe the process of interpretations on the subject matter through which the participants construct their actions (e.g., body language, facial expressions, and gestures). Additionally, the Darwinian perspective postulates emotions as evolved phenomena with important survival functions that have been selected for because they have solved certain problems we have faced (Darwin, 1965). In constructivism's paradigm, the individual is not a passive recipient of a set meaning but an active, resourceful, and reflective participant in the construction of meaning (Charon, 2001). All of these theoretical frameworks in the cognitive approach are suitable for the purpose of this study in disclosing meanings and perceptions of participants via interviews, projection of thoughts on Edmodo, and interpretations by means of actions.

Sampling. Purposive sampling was employed in order to yield the best understanding in this study (Fraenkel \& Wallen, 2003). Therefore, four undergraduates, with pseudonyms of Rose, Fatin, Farah, and Emme, from the Faculty of Education at the University of Malaya were selected as participants for this six-month research. This research used Edmodo for language learning and aimed to capture participants' views regarding its implementation. Participants were chosen due to their status of being both students and future teachers who could reflect on and utilize existing knowledge in comparing teaching methodologies learned from the course with the relevance of using Edmodo for education. The research draws heavily on the qualitative study method that focuses on examining the perceptions of participants. Furthermore, researchers were advised to conduct interviews to gather data qualitatively because perceptions collected in quantitative representations do not clearly ascertain students' reasons for their beliefs (Gamble et al., 2013). 
Data analysis and procedure. The instruments included the researcher (Yin, 2011), interview protocols (Jacob \& Ferguson, 2012), concept maps (Malek, 2002), and photographs (Dzakiria, 2008). This study examined the subject matter with interpretive and naturalistic approaches in order to explore the participants' views in the most natural manner. Inductive logic was employed because it allows issues, categories, and themes to emerge from the experiences of participants in the study (Dzakiria, 2004). It was crucial to approach the phenomenon in a natural setting, without any presumptions, to ensure neutrality in reporting the data. In order to comprehend participants' views in the most comprehensive way possible, qualitative research provided the appropriate approach. Further, Creswell (1998) describes qualitative study as an inquiry process of understanding that explores an area of study.

The study then executed open coding to identify the emerging themes; axial coding, which focused on finding the themes' consistency; and selective coding, whereby core categories were selected in order to explain Edmodo's effects (Strauss \& Corbin, 1990). Open coding is a process that consists of naming and categorizing a phenomenon via intense examination of the data (Strauss \& Corbin, 1990). As this study included photographs, data was skimmed through and categorized into possible main ideas that would connect it to the interviews' central themes. The next advancement in the classification of data is known as axial coding. Using this method, data was triangulated to confirm the interrelationships between themes and ensure consistency. This process is similar to open coding but with more details and attempts to narrow down the categories, subcategories, and properties of the said categories and subcategories (Strauss \& Corbin, 1990, p. 97). Next, selective coding involved choosing core categories that would represent smaller categories and subcategories of the aforementioned core categories. These core categories, in which each has its own smaller elements and central ideas, have the ability to answer all the research questions and accomplish the objectives of this study (Strauss \& Corbin, 1990).

Throughout the process of perusing data and findings, the interpretive method was adopted (Walsham, 1993) because it allowed interpretation of data from the researcher's point of view while revealing multiple realities of the participants involved. The interpretive perspective relies on the notion that qualitative research should reveal multiple realities of the people involved, as opposed to capturing the objective reality. This is due to the fact that objective reality can never be captured (Denzin, 2010). The narrative approach became the technique for conveying information, ensuring factuality that mirrors upon the participants' point of views (Lauritzen \& Jaegar, 1997).

Ethical issues. For the purpose of this research, two areas of ethics were considered: consent and the confidentiality of participants' personal information, because a researcher must acquire consent to avoid conflicts of interest (Corti, Day, \& Backhouse, 2000), University of Malaya (as the selected site for this study) had been informed of the research's nature, procedure, and intended sampling. Acquiring permission from the institution concerned was a highly significant part of the ethical considerations; therefore, the university was approached prior to contacting the participants.

Subsequently, informed consent forms were acquired from the participants at the beginning of the research. The form illuminated the scope of study, duration, risks, compensation, and confidentiality. In this way, participants had knowledge of the structure of the research they would be participating in. Providing informed consents allowed for honesty and 
transparency, as participants were aware of what was expected of them throughout the course of study (Sieber, 1993).

Meanwhile, the participants' confidentiality was assured. In this research, participants and the researcher were involved in informal meetings where discussions about their perspectives took place. Therefore, full disclosure from the participants was required in order to explore their deepest thoughts, which could involve sensitive issues to outsiders (Dzakiria, 2008). Hence, protecting their shared opinions and personal information was a priority.

Reliability and validity. Concept maps were used to represent participants' closing thoughts on Edmodo in a simpler form and was one of the methods used to ensure reliability for triangulation of data. The use of concept mapping in this study helped participants to organize their final thoughts and made it easier for the researcher to comprehend their conclusions (Solvie \& Sungur, 2006). Concept maps were utilized to compare and contrast the themes that emerged from the interviews. To ensure validity, the researcher reaffirmed the emergent themes gathered from analyses with the participants by inquiring if the research findings and interpretations were parallel to participants' perceived views. Responses obtained from the participants indicated that the research findings are indeed equivalent to the perceptions they conceived and shared about Edmodo. Figure 1 shows their replies regarding the research findings:

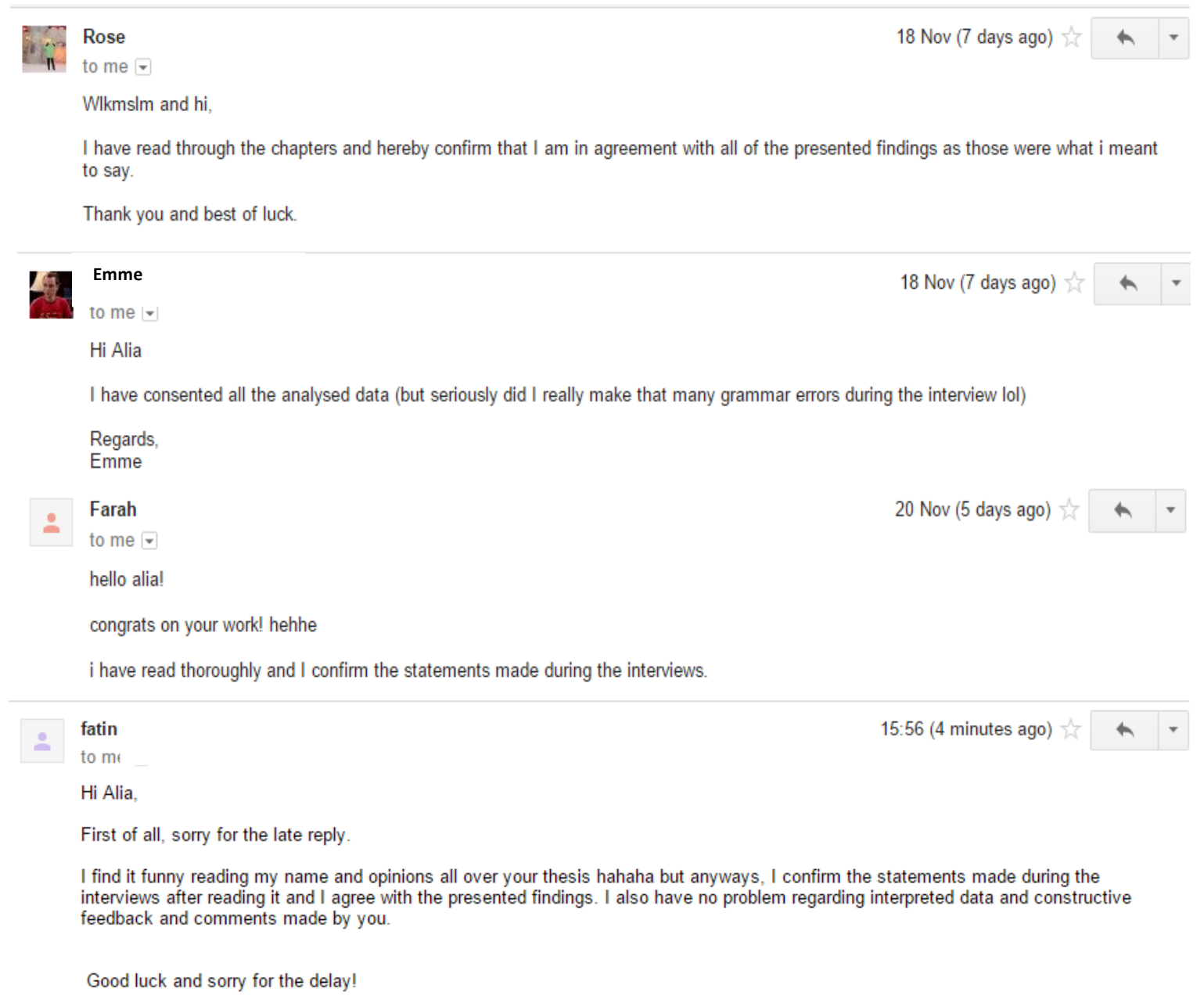

Figure 1. Participant responses to inquiries regarding validity of research findings. 


\section{Results}

Ensuring the implementation of appropriate digital designs and students' access to education outside of the physical classroom are crucial for their learning outcomes. This research revealed three significant features of Edmodo that may enhance learning experiences - namely, novelty of tasks, favorable learning environment, and mobility.

\section{Novelty of Tasks}

One of the many ways Edmodo helps to break barriers in the conventional classroom is by offering an abundance of tasks that are within teachers' and students' locus of control, which is an element not available in social network platforms. The participants shared one of the features that aids in enhancing learning experience, which is quick buttons for creative assessments (Hung \& Khine, 2006). Choices of assessments on Edmodo may vary depending on teachers' objectives for the lesson and include options such as fill in the blanks, multiple-choice questions, true-false, short answer, matching, poll, assignments, and many others. These materials allow teachers to create resourceful tasks and engage students in activities beyond the confined classroom. Additionally, participants agreed that Edmodo may help reducing workload, as teachers do not have to print worksheets, make copies, distribute them to students, and discuss the answers in the next lesson. Rather, teachers can simply create assessments and post them on Edmodo, while concurrently allowing students to do the assessments at their own pace and comfort. Moreover, at the end of the task, Edmodo will show the correct answers along with areas/questions that students answered incorrectly, which will indirectly help by giving students constructive and corrective feedback they need in order to progress in learning effectively.

Below are excerpts where participants shared their views on the advantages of engaging activities on Edmodo. A participant named Fatin commented that interactive quizzes that provide feedback at the end of the task serve as good ongoing exercises for summative assessments. Meanwhile, Emme contended that quizzes evoke a feeling of excitement as students are completing it:

Quizzes help make learning interactive. You (the researcher) also gave us the fillin-the-blank task, which in my opinion, such assessment offers freedom for the students to give answers, and in the last part of the task they'll know about their overall performance. Through this way, they are learning in an informal environment and able to improve themselves too at the end of the task. Plus, it has time limit, it's good because it teaches students to answer questions within the time given, therefore it's a good preparation and practice for summative assessments. (Fatin)

I learned that we can do quizzes through Edmodo and finish it within the time given. Generally, it's exciting because it makes students focus and think faster. (Emme)

Additionally, Figure 2 illustrates the corrective feedback for students upon finishing the assigned quiz where Edmodo shows the questions and answers along with indications on which questions students answered wrongly. 


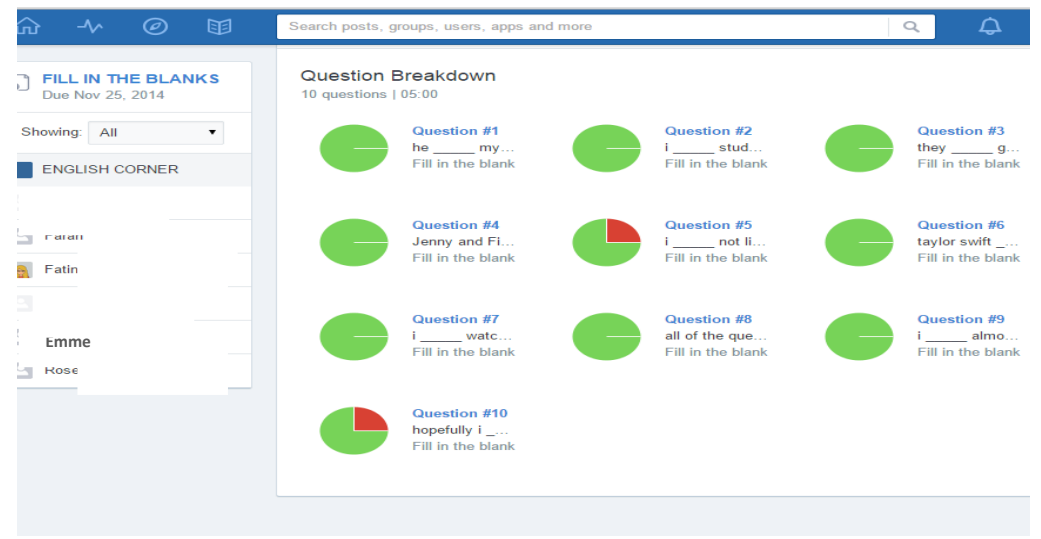

Figure 2. Corrective feedback.

In addition, a participant named Farah said that besides quizzes, the poll is another noteworthy feature on Edmodo which makes teaching and learning interactive as well as less time-consuming as opposed to gathering feedback by going through every student in the classroom:

Quizzes are really fun and the 'poll' feature is also noteworthy because you can get quick opinions just by voting. (Farah)

Further, Figure 3 demonstrates how the poll feature appears on the platform, which is followed by the comments section, whereby students may discuss and interact with peers about the poll posted. All of these aspects contribute to be a form of novelty of tasks on Edmodo.

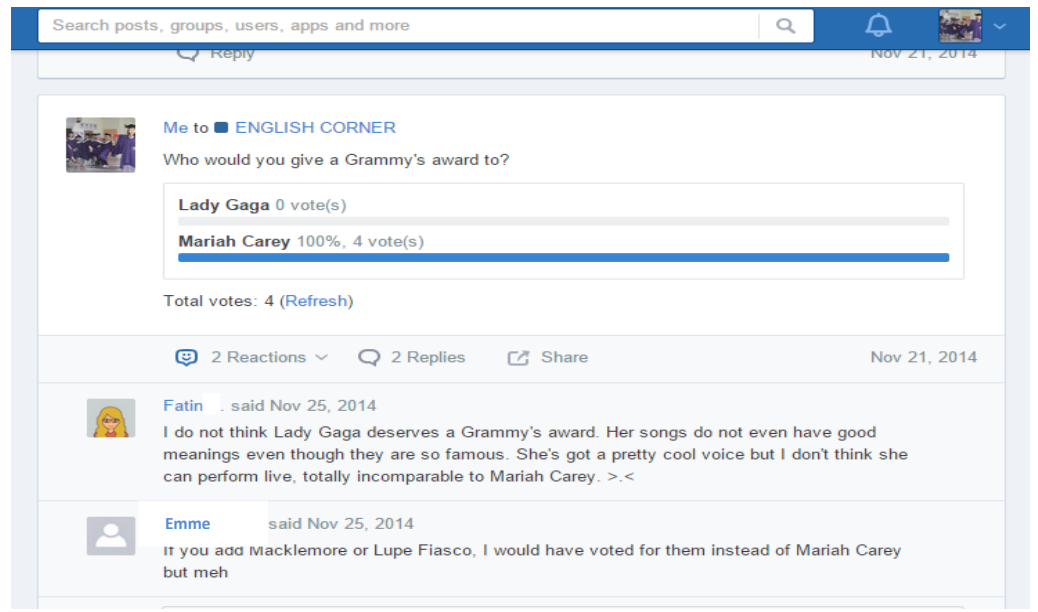

Figure 3. Edmodo poll.

Participants further commented on the "reaction" and "badges" buttons, where teachers may give immediate response and feedback. In a physical classroom, teachers usually give feedback, compliments, and comments in the exercise books after assessing the work submitted by students (Woroniecka, 1998). Edmodo uses the same idea for teachers to give responses, but in a digital form. Giving credit to students when it is due is significant, as it boosts their intrinsic motivation to do better and learn from their mistakes. These features are an example of gamification, whose goals are to maximize enjoyment and engagement through 
capturing the interest of learners and inspiring them to continue learning (Kiryakova, Angelova, \& Yordanova, 2014).

A participant shared that gamification on Edmodo is appealing and engaging when she wants to respond on a post's thread, while another participant named Fatin thinks gamification is an excellent approach to giving feedback to students as well as providing students with the emotional support they need in their learning process:

In terms of fun, there's a 'reaction' button, I thought that is cute and quick as you can give emoticons as a response on the thread. (Farah)

Teachers can give compliments to students if they participated in discussions because it has a feature where it can give badges to students. It's similar to drawing 'stars' in their exercise books after checking and marking their assignments. I do think students like to be praised and those badges may boost confidence and motivate them to accomplish tasks. (Fatin)

Figure 4 displays how gamification looks on Edmodo, where each reaction carries a meaning in order to help students and teachers to easily understand what the reaction/emoji means.

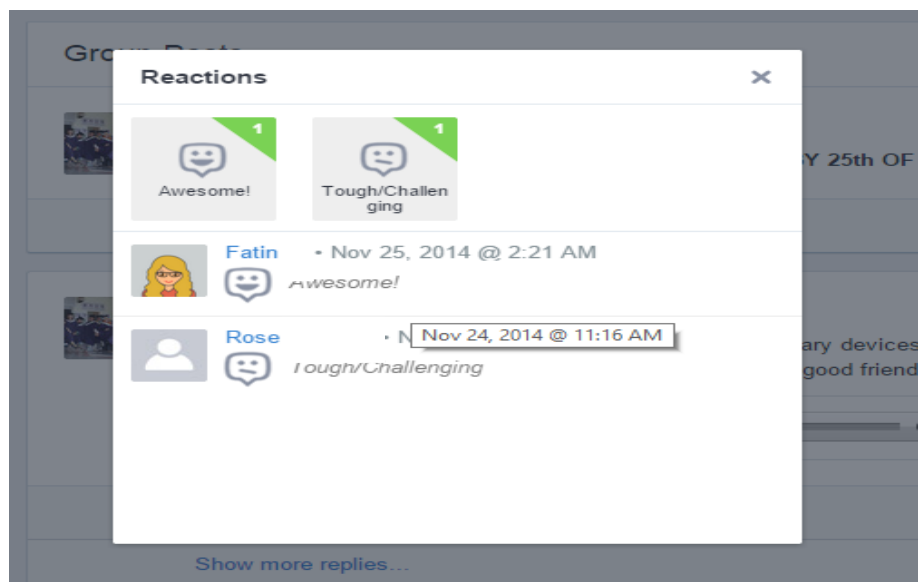

Figure 4. Reaction button.

Contrary to the drilling of reading and writing activities in a physical classroom, which cause students to be easily bored (Wang, 2007; Chu, 2001), Edmodo offers various types of assessments that will be appealing and attractive to enhance students' learning experiences. Participants further remarked on these features on Edmodo that assist in the creation of innovative and authentic assessments:

If the teacher posts music clips, you can listen to it as well. You (the researcher) asked us to listen to the friendship song (one of the assessments), I listened to it many times as the song was nice and I learned about the messages and themes the singer wants to convey. Besides, it's entertaining as you get competitive with your friends, you can observe who did best and who already sent in their work. (Farah)

Edmodo also has a feature where you can create many kinds of tasks, thus I believe students will not get bored doing different virtual activities. (Fatin) 
Authentic and diverse assessments are deemed prominent in assisting students in their learning outcomes. Engaging students beyond the physical classroom and allowing them to improve themselves via virtual tasks are excellent teaching and learning strategies in guaranteeing better results in education. Participants' emotions regarding the novelty of tasks may be linked to the aforementioned Darwinian perspective, which postulates emotions as evolved phenomena with important survival functions that solved certain problems we have faced (Darwin, 1965). Edmodo's features are profoundly helpful for improving students' retention rate, engrossing them in the lessons, and fulfilling their emotional needs when teachers provide positive reactions.

\section{Favorable Learning Environment}

Edmodo's involvement in the learning process can be manifested via the suitable learning environment it provides. For example, its atmosphere is conducive to learning due to positive feedback, acceptance, climate, and culture, resulting in peer tutoring and student engagement. In addition, students feel at ease conversing and conducting discussions among themselves due to the reassuring and informal setting of the virtual classroom:

Through Edmodo, students can see the lessons become quite informal; it's more on acquisition of knowledge and learning process. They know that learning doesn't stop in class, there's a website they can independently explore to do tasks and improve themselves. (Emme)

It's both formal and informal at the same time. It seems like you are logged in to your social networking site but the content is educational. (Fatin)

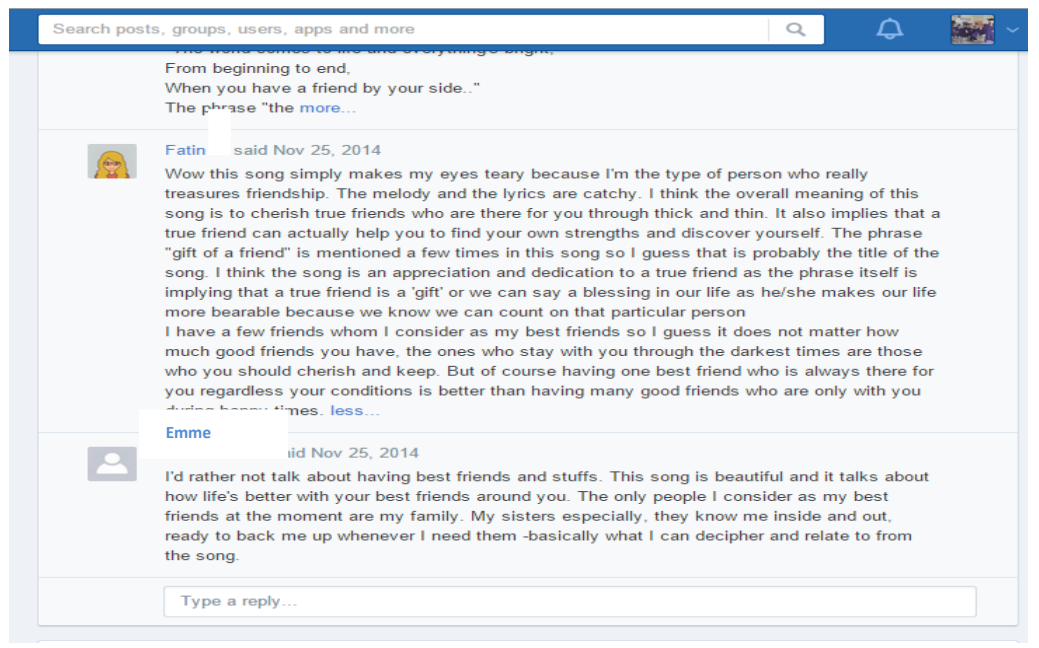

Figure 5. Example of student engagement.

Emme and Fatin posited that Edmodo provides an informal environment and extended lessons after school hours, which resulted in providing a safe haven for learning as well as feeling welcomed and independent in navigating their learning process. In Figure 5, we may discern how participants openly shared their feelings and personal recollections. Such activity indirectly helps to create strong engagement among students in the lesson. We can also witness how they conversed naturally in an informal manner yet were able to use proper language items, indicating that they know how to communicate effectively with the target audience. Fatin also 
added that such an environment may help some struggling students who refuse to talk in public due to lack of confidence:

Its informal environment enhances learning by helping students who are shy to talk, not participating in class and lack of confidence to express their opinions. For example, when the teacher assigns tasks on Edmodo, maybe those students will get to express and exchange ideas better. Later on, it will boost their confidence level and will be able to speak comfortably in public.

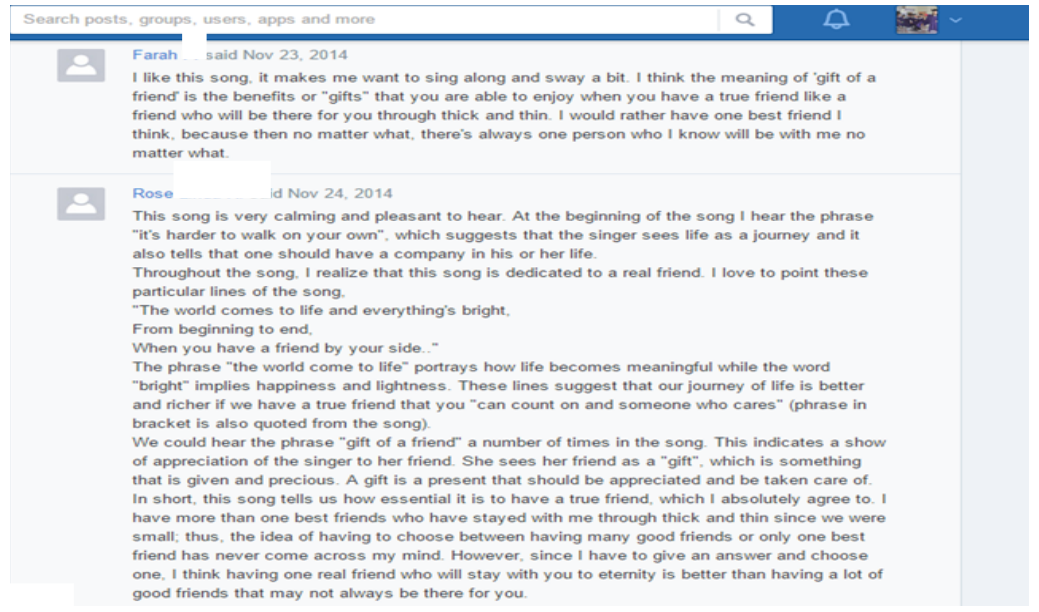

Figure 6. Learning environment.

Likewise, Figure 6 supports the idea that Edmodo offers a favorable learning environment where participants get to share their thoughts while benefitting from the activity. In addition, Edmodo is able to convey a momentous change in terms of learning experience. The atmosphere that it provides is said to be healthy and refreshing, as described by Farah and Emme.

The essence of Farah's following response is that Edmodo allows a getaway from the normal physical classroom situations, while Emme stresses the importance Edmodo's capacity to facilitate healthy discussion, because she feels most at ease debating and conveying her ideas without upsetting classmates or friends with her honest opinions:

I found that in terms of learning; it's new, refreshing and fun. When I said it's new, it's because Edmodo is a social learning platform and not the conventional classroom. (Farah)

I think Edmodo provides a healthy environment because if I were to discuss with my friends whom I know well, some of them might get offended with what I say and really get emotional at certain point. Thus, I prefer not knowing personally whom I am interacting with on Edmodo because the conversation becomes more neutral as other commentators could be strangers or merely online classmates whom I do not meet or friends with outside of the learning platform. Besides that, I can have a nickname on Edmodo and be more comfortable in sharing my opinions without having to be worried about my identity known to others or upsetting my peers. (Emme) 
Additionally, Farah's concept map is bursting with her perceptions of Edmodo as being fun and interactive as she comments on the tool's flexibility in allowing pictures and songs to be shared, good practice for language skills, competitive in a healthy way, and having benefits in terms of peer review. Her concluding concept map elaborately illustrates how she views Edmodo as a suitable tool for students' education.

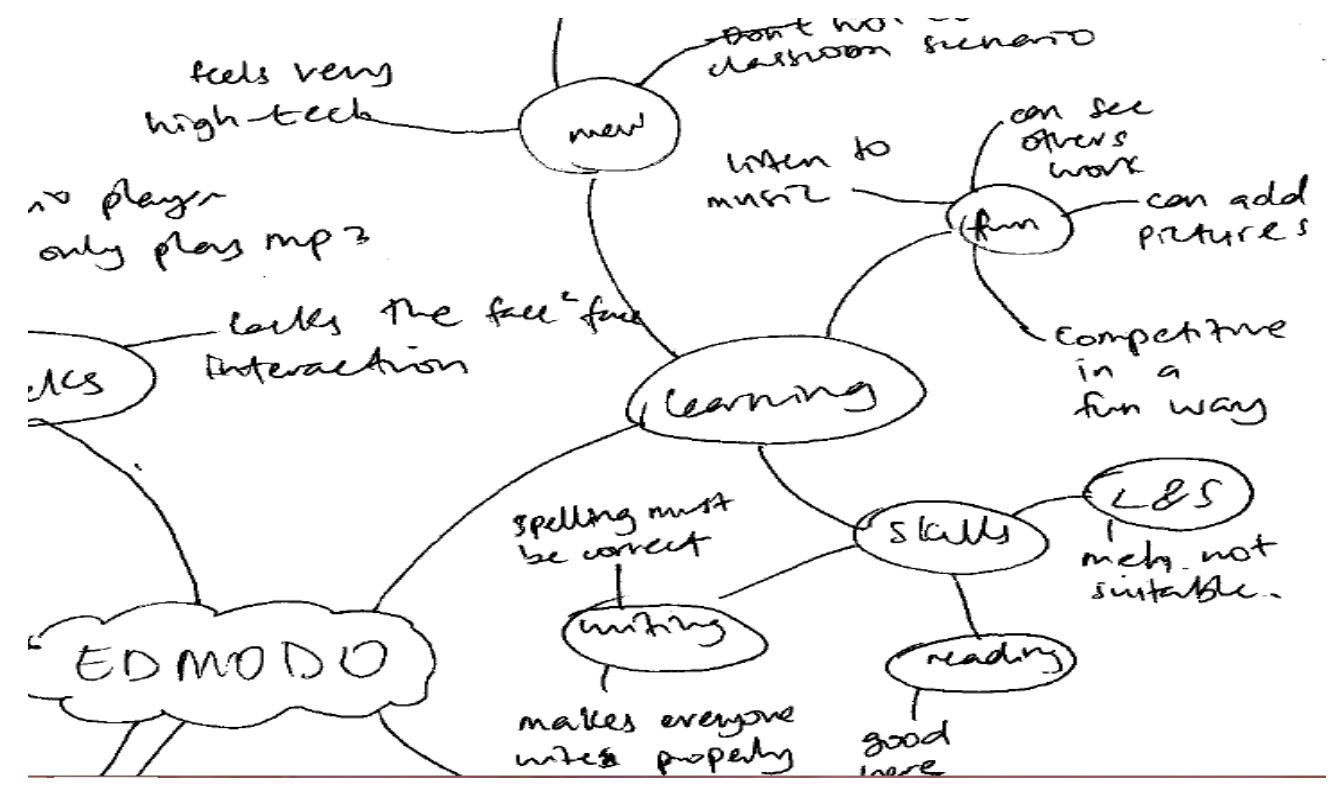

Figure 7. Farah's concept map about Edmodo: Fun and interactive.

Retrospectively, analyzing participants' opinions shows that Edmodo is conceived to be a refreshing site that provides a healthy learning environment, which consequently implies that Edmodo is apt for teaching and learning purposes. It turns into a change agent and motivator in transforming traditional instructional models by permitting learners to be actively involved in their learning inside and outside of the classroom (Wallace, 2014; Dobler, 2012).

\section{Mobility}

Allowing students to be mobile and connected to their education is another integral theme in improving students' learning strategies. Mobility is reckoned as an important characteristic for learning because it allows students to learn at own pace and face less disruption in their daily schedules because they may easily log into Edmodo using any Internet-connected digital device:

More freedom as I can be mobile, do tasks anywhere at any time. (Farah)

You can even log in through your mobile phone, so I think it's made easier rather than meeting face to face. It makes learning easier and more interactive. (Fatin)

Edmodo enables seamless learning opportunities in different situations, as it is available on mobile phones, iPods, iPads, or any other smart gadgets (Lu \& Churchill, 2013). This has become one of the prominent advantages of implementing Edmodo, because both educators and students will get the chance to acquire constant access to education, assignments, progress, updates, and announcements. 
Additionally, Fatin intensely appreciated advantages from such a learning platform due to her hectic schedule. According to her, the site gives her an opportunity to stay connected and be involved while maintaining her agenda as an active student on campus:

Edmodo enhances learning and takes education to a whole new level. I find it flexible because you can do tasks anytime and anywhere because I am actually quite a busy student as I am involved with sports and other activities. This site encourages me to do assessments and tasks according to my time. I can plan when and how to do my tasks, therefore it is very convenient for me. (Fatin)

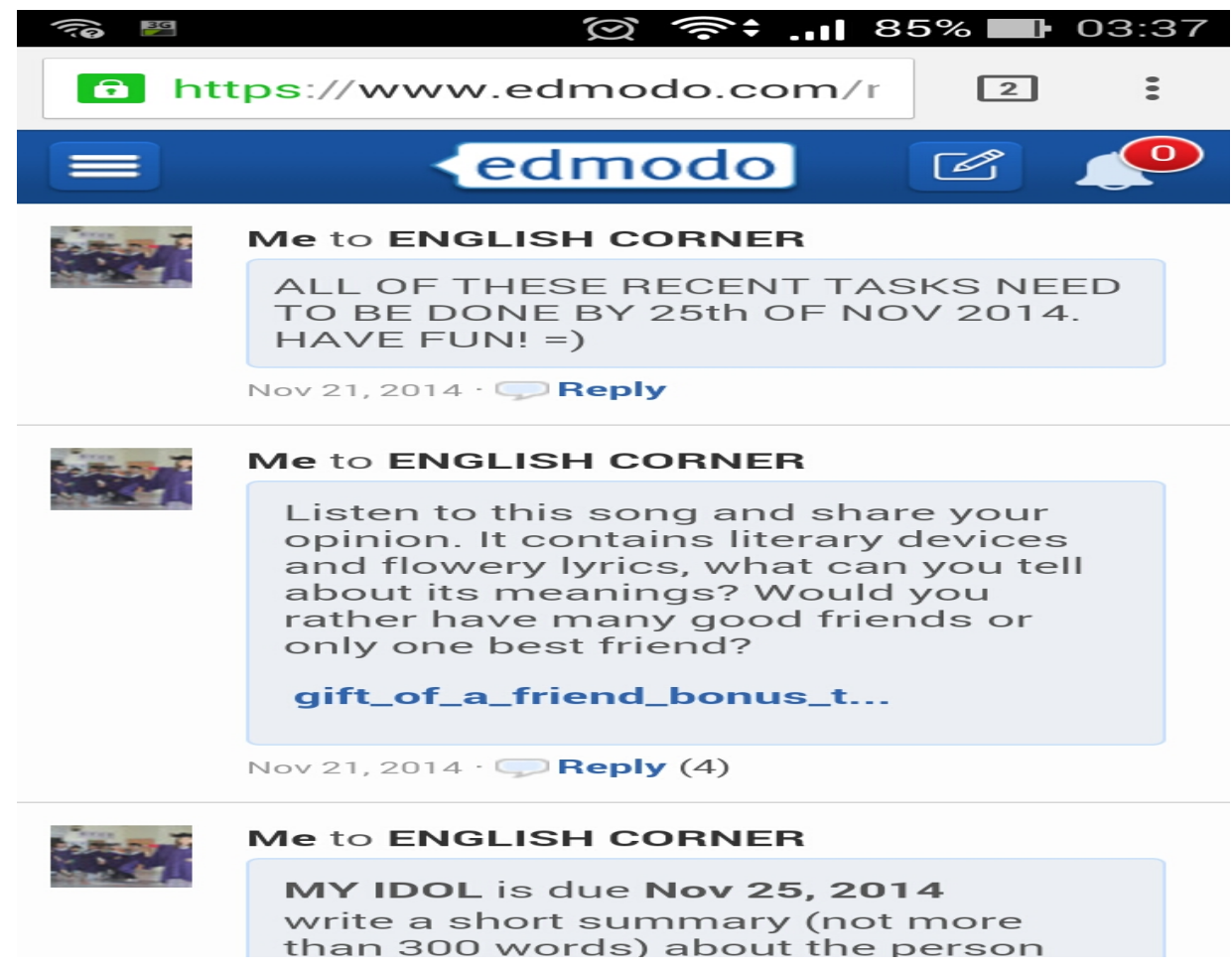

Figure 8. Illustration of Edmodo's mobility.

Figure 8 depicts how Edmodo looks on a smartphone. The overall outlooks on mobile devices are very minimalistic, yet within students' locus of control. This means the features on mobile version are not as clear or fully available compared to the desktop version. However, despite the limitations, the mobile version still manages to support important features, such as posting, updating, responding, and viewing threads. Consequently, Edmodo's mobile version provides a good learning experience while allowing students to be flexible with their daily schedule yet connected to their education anytime and anywhere. The theme of the importance of mobility may be associated with the chosen theoretical approach in the study, whereby the cognitive perspective emphasizes the connections between thought and emotion. This perspective views all emotions as being dependent on appraisal, the process by which events in the environment are judged as good or bad by those who experience them (Arnold, 1960). Participants in this study evidently prefer to have more freedom and autonomy as to when and how they may enhance their learning experience; therefore, constructivism is the apt theoretical approach because it is able to explain participants' emotions pertaining to the theme of mobility (Charon, 2001). 
In a nutshell, these three core themes help in assisting students to remain connected to their education. The supports are Edmodo's capacity to allow mobility, provide a favorable learning environment, and offer novel tasks, which resulted in students feeling relaxed and engaged. These features permit students to gain a sense of tranquility, learn appropriate skills, and be amused while they are on the site (Thien et al., 2013). Due to all of the themes identified above, participants deemed Edmodo to be properly equipped to help students stay connected and retain information longer.

\section{Discussion}

Edmodo is an example of a social learning platform that converts the practice of conventional teaching and assists in the quest of knowledge seeking when it is employed to conduct assessments after classroom hours by broadening the amount of resources available to the students, especially with the advancement of Internet and web-based applications (Rais \& Hashim, 2004). Through Edmodo, students can go beyond the textbook while having an authentic learning experience, and ensuring engagement with students' learning curve can further be enhanced with properly designed assessments (Hung \& Khine, 2006). Edmodo provides a feature where interactive assessments can be easily made; it is all just a click away. As students facilitate their own discussions and learning, the educator's role is to monitor the progress and ensure no students fall out of the topic or deviate from the focus of the tasks assigned. At present, rote learning is no longer appropriate; therefore, providing diverse assignments is important. Students who are engaged and immersed with their learning curve will share more of their recollections in terms of their personal experience, new inputs that they encounter, photos, documents, and many other things, as there is a sense of trust in the online community (Anderson, 2010).

Meanwhile, Hung and Khine (2006) state that "engagement with learning is likely to mean engagement with technology" (p. 9). The notion denotes that learners need to be engaged with technology in order to have a holistic and encouraging engagement with learning. Moreover, the practice of individual competition can be decreased by having more collaborative efforts with peers. Group work is often disregarded when teachers are more concerned about individual achievements, which stimulates competition between individual students (Slavin, 1995). Therefore, two-way interactions on Edmodo may give students a voice and liberate them to have autonomy on their personal learning curve (Wahit \& Mohd, 2013). In addition, allowing students to gain an access to their education helps in lowering negative perceptions, low cognitive achievements, and undesirable attitudes (Victori \& Lockhard, 1995).

Further, participants posited that one of the most supportive features of Edmodo is the capacity for students to be mobile while having freedom to access the site anytime and anywhere. Appraisal on this particular feature transcends what participants in this study commented, as other researchers similarly obtained and emphasized on the same theme: mobility (Chandler \& Redman, 2013; Lu \& Churchill, 2013). Further, mobility enables seamless learning opportunities, which bring students closer to their education (Bledsoe \& Simmerok, 2013). In review, mobility is an essential aspect that permits learners to always have the capacity to access their education at their convenience. Additionally, in the digital world we live in today, providing continuous openings for students to be mobile while connected to their learning experience should be easily made possible, particularly with the advancements of Web 2.0 tools, social learning networks, and many others. 
Besides these benefits, students' attitudes have been proven to be a strong motivation for the use of online social platforms (Shittu, Gambari, \& Sule, 2013), and perceptions collected in qualitative representations do visibly ascertain students' reasons for their beliefs (Gamble et al., 2013). Therefore, through this study on Edmodo, we have been enlightened on many features that are usually available on social learning platforms, which may assist in ensuring optimum learning outcomes. We have also learned how and why such feelings emerge. Moreover, the participants explicitly illustrate their learning experience on the site, which is significantly beneficial in understanding how online learning takes place and what method is preferred by learners.

\section{Limitations and Recommendations}

Even though Edmodo provides support for students to gain more access and autonomy, it is also noteworthy that every learner does have their own preferences in learning. Lamboy (2003) criticizes how universities have been slow in planning for students' diverse learning styles and adopting new technologies for teaching tactics. This is supported by Dille and Mezack (1991), who argue that technology does have a tremendous relation to students' learning style preferences, which consequently leads to their academic performance. In many cases, Edmodo can be one of the possible solutions to equip and expose students to an out-of-classroom experience, yet what is ideal is a matter of perspective and preference of individuals (Pasch, Langer, Gardner, Starko, \& Moody, 1995).

Future studies regarding the use of social learning platforms through Edmodo should attempt to acquire a larger number of participants and diversify their backgrounds. Besides that, other learning materials, such as mathematics, biology, arts, and other subjects, should be tested on the site as well. Time constraint is the main restriction, because with more time, perhaps additional effects or opinions can be obtained. Perceptions of teachers should also be an interesting realm of study related to the implementation of Edmodo. In a nutshell, future studies should look into Edmodo over a longer period with students from several institutions as well as with more participants and researchers from other fields besides language.

\section{Conclusion}

In a nutshell, besides the advantages that Edmodo offers users through the diversity of features, it ultimately helps to close the gap between students and their access to education. Wider access to one's education demands willingness to take on more responsibilities and to explore on one's own. Therefore, all of the available options on the site may assist the teaching and learning process and transform students' learning curve to be more comprehensive, holistic, and complete. Digital natives of today would very much appreciate the implementation of social learning platforms, such as Edmodo, because of the benefits they offer. The pedagogical implications of this research are related to how Edmodo may enable students to access learning resources beyond the classroom, and empower student-centered learning. Additionally, with the increased use of technological tools in education, practitioners may find this work interesting as an alternative for students' perusal. This paper has illuminated the techniques Edmodo may assist students' engagement in learning, which essentially is accomplished through a variety of tasks, a suitable learning environment, and mobility. It is evident that Edmodo closes the gap between students and access to their education through the methods described above. 


\section{References}

Akbar, H. A., Purwarianti, A., \& Zubir, H. Y. (2013). Development of e-learning with social network. Joint International Conference on Rural Information \& Communication Technology and Electric-Vehicle Technology (pp. 1-6). Retrieved from http://ieeexplore.ieee.org/document/ 6741558/

Anbe, G. (2013). Using Edmodo to incorporate WICOR strategies in the AVID classroom. In TCC Conference (pp. 1-9. Retrieved from https://scholarspace.manoa.hawaii.edu/bitstream/10125/27127/1/Anbe_Final.pdf

Amrein-Beardsley, A., Foulger, T. S., \& Toth, M. (2007). Examining the development of a hybrid degree program: Using student and instructor data to inform decision making. Journal of Research on Technology in Education, 39(4), 331-357.

Anderson, M. A. (2010). Expanding the power of primary sources with Web 2.0. The Media Center, 1-3.

Arnold, M. (1960). Emotion and personality (Vol. 2). New York: Columbia University Press.

Beldarrain, Y. (2006). Distance education trends: Integrating new technologies to foster student interaction and collaboration. Distance Education, 27(2), 139-153. doi:10.1080/01587910600789498

Bledsoe, T. S., \& Simmerok, B. D. (2013). A multimedia-rich platform to enhance student engagement and learning in an online environment. Journal of Asynchronous Learning Networks, 17(4), 1-10. Retrieved from https://olj.onlinelearningconsortium.org/index.php/olj/article/view/398

Business Wire. (2014, August 6). Edmodo hosts fourth annual EdmodoCon bringing together more than 42,000 educators worldwide. Retrieved from http://www.businesswire.com/news/home/20140806005964/en/Edmodo-HostsFourth-Annual-EdmodoCon-Bringing-42000

Chandler, P. D., \& Redman, C. (2013). Teaching teachers for the future: Modeling and exploring personal networks. Australian Educational Computing, 27(3), 54-62.

Charon, R. (2001). Narrative medicine: A model for empathy, reflection, profession, trust. JAMA, 286(15), 1897-902.

Chu, M. P. (2001). Applying process writing as a cooperative learning strategy to the ESL/EFL writing class. Hwakang Journal of English Language \& Literature, 7, 27-39.

Corti, L., Day, A., \& Backhouse, G. (2000). Confidentiality and informed consent: Issues for consideration in the preservation of and provision of access to qualitative data archives. Forum: Qualitative Social Research, 1(3).

Creswell, J. W. (1998). Qualitative inquiry and research design: Choosing among five designs. Thousand Oaks, CA; Sage.

Crotty, M. (1998). The foundations of social research: Meaning and perspective in the research process. London: Sage Publications. 
Dalsgaard, C. (2008). Social networking sites: Transparency in online education. Proceedings From EUNIS 2008 VISION IT. Retrieved from http://eunis.dk/papers/p41.pdf

Darwin, C. (1965). The expression of the emotions in man and animals. Chicago: University of Chicago Press.

Denzin, N. (2010). On elephants and gold standards. Qualitative Research, 10, 269-272.

Dille, B., \& Mezack, M. (1991). Identifying predictors of high risk among community college telecourse students. The American Journal of Distance Education, 5(1), 24-35.

Dobler, E. (2012, February). Flattening classroom walls: Edmodo takes teaching and learning across the globe. Retrieved from

http://www.dentonisd.org/cms/lib/TX21000245/Centricity/Domain/3150/Flattening\%20C lassroom $\% 20$ Walls.pdf

Dzakiria, H. (2004). The teacher is always there, but isn't: Distance learners' perspectives on distance learning at Universiti Utara Malaysia (Unpublished doctoral dissertation). Universiti Utara Malaysia, Sintok.

Dzakiria, H. (2008). Pragmatic approach to qualitative case study research learning by doing: $A$ case of distance learning research in Malaysia. Sintok: Universiti Utara Malaysia Press.

Edmodo. (2016). About Edmodo: How we got started. Retrieved from https://www.edmodo.com/about

Edmodo. (2018). About Edmodo. Retrieved January 18, 2018, from https://www.edmodo.com/about

Electronic Education Report. (2014, January 31). EER takes a look at popular education apps. Retrieved from http://www.electroniceducationreport.com/content/eser-takes-lookpopular education-apps

Fraenkel, J. R., \& Wallen, N. E. (2003). How to design and evaluate research in education (5th ed.). New York, NY: McGraw Hill Higher Education.

Gamble, C., Aliponga, J., Koshiyama, Y., Wilkins, M., Yoshida, K., \& Ando, S. (2013). University students' beliefs, perceptions and attitudes towards communicative language teaching. MEXTESOL, 32(2).

Geron, T. (2011). Edmodo wants to make social networking a learning experience. Forbes. Retrieved from https:/www.forbes.com/sites/tomiogeron/2011/08/24/edmodo-wants-tomake-social-networking-a-learning-experience/

Hung, D., \& Khine, M. S. (Eds.). (2006). Engaged learning with emerging technologies. Netherlands: Springer.

Jacob, S. A., \& Furgerson, S. P. (2012). Writing interview protocols and conducting interviews: Tips for students new to the field of qualitative research. The Qualitative Report, 17, 110. Retrieved from http://files.eric.ed.gov/fulltext/EJ990034.pdf

Lamboy, C. L. (2003). Using technology in an English as a second language course to accommodate visual, kinesthetic, and auditory learners to affect students' self-efficacy about learning the language (Unpublished doctoral dissertation). Nova Southeastern University, Fort Lauderdale, FL. 
Lauritzen, C., \& Jaeger, M. (1997). Integrating learning through story: The narrative curriculum. Albany, NY: Delmar.

Lu, J., \& Churchill, D. (2013). Creating personal learning environments to enhance learning engagement. Proceedings of the 63rd Annual Conference International Council for Educational Media (ICEM). Retrieved from http://toc.proceedings.com/22321webtoc.pdf

Mazer, J. P., Murphy, R. E., \& Simonds, C. J. (2007). I'll see you on "Facebook": The effects of computer-mediated teacher self-disclosure on student motivation, affective learning, and classroom climate. Communication Education, 56(1), 1-17.

McClain, C., \& Brown, A. (2013). Literature 2.0: An exploration of character using Edmodo. Proceedings of the 18th Annual Research Forum, Department of Education, Wake Forest University, Winston-Salem, NC, June 26, 2013, 55-60.

Moore, D. (2017, January 24). Using Skype for business: Features, limitations and alternatives. Retrieved from https://www.linkedin.com/pulse/using-skype-business-featureslimitations-darlene-moore

Kiryakova, G., Angelova, N., \& Yordanova, L. (2014). Gamification in education. Proceedings of 9th International Balkan Education and Science Conference. Retrieved from http://dspace.uni-sz.bg/bitstream/123456789/12/1/293-Kiryakova.pdf

Malek, S. (2002). Reducing cognitive load using concept maps (Unpublished master's dissertation). Fakulti Sains Komputer dan Teknologi Maklumat, Universiti Malaya, Kuala Lumpur.

Pasch, M., Langer, G., Gardner, T. G., Starko, A. J., \& Moody, C. D. (1995). Teaching decision making: Successful practices for the elementary teacher. New York, NY: Longman.

Rais, M., Karim, A., \& Hashim, Y. (2004). The experience of the e-learning implementation at the Universiti Pendidikan Sultan Idris, Malaysia. Malaysian Online Journal of Instructional Technology, 1(1), 50-59.

Rivero, V. (2013). Tools for learning: Meaningful connections - What's new in the social media sphere? Internet@Schools Magazine. Retrieved from http://www.internetatschools.com/ Articles/Editorial/Features/TOOLS-FOR-LEARNING-Meaningful-ConnectionsWhats-New-in-the-Social-MediaSphere-93158.aspx

Shachter, R. (2011). How to use technology to connect your students to a larger world. Kid to Kid Connections, 1-3. Retrieved from http://files.eric.ed.gov/fulltext/EJ945712.pdf

Shittu, A. T., Gambari, A. I., \& Sule, A. O. (2013). Students' attitude and behavioural intention on adoption of Internet for learning among Al-Hikmah University Students in Nigeria: A test of technology acceptance model. Malaysian Journal of Distance Education, 15(2), 89-107. Retrieved from http://mjde.usm.my/vol15_2_2013/6-MJDE-v15n2.pdf

Sieber, J. (1993). The ethics and politics of sensitive research. In C. Renzetti \& R. Lee (Eds.), Researching sensitive topics. London: Sage Publications.

Slavin, R. E. (1995). Cooperative learning: Theory, research and practice. (2nd ed.). Boston: Allyn and Bacon. 
Solvie, P. A., \& Sungur, E. A. (2006). Concept maps/graphs/trees/vines in education. Journal of Science and Mathematics, 220-228.

Stracker, C. M. (2011). Open learning: The concept for modernizing school education and lifelong learning through the combination of learning innovations and quality. Official Proceedings for the International EIF/LINQ Conference 2014, (pp. 1-21). Retrieved from https://www.researchgate.net/publication/306031759 Open_Learning The Concept for Modernizing_School_Education_and_Lifelong_Learning through the Combination_of Learning_Innovations_and_Quality

Strauss, A., \& Corbin, J. (1990). Basics of qualitative research: Grounded theory procedures and techniques. Newbury Park, CA: Sage Publication.

Sulleyman, A. (2017, 7 November). Twitter introduces 280 characters to all users. The Independent. Retrieved from http://www.independent.co.uk/life-style/gadgets-andtech/news/twitter-280-characters-tweets-start-when-get-latest-a8042716.html

Tidwell, L. C., \& Walther, J. B. (2002). Computer-mediated communication effects on disclosure, impressions, and interpersonal evaluations: Getting to know one another bit at a time. Human Communication Research, 28, 317-348.

Thien, P. C., Phan, L. Van, Loi, N. K., Tho, Q. T., Suhonen, J., \& Sutinen, E. (2013). Applying Edmodo to serve an online distance learning system for undergraduate students in Nong. Proceedings of the IETEC'13 Conference, PHAM Cong Thien, 1-15.

Tomassini, J. (2013). Edmodo now closer to social network. Australian Educational Computing, 27.

UNESCO. (2004). Integrated ICT into education: Lessons learned. Bangkok, Thailand: UNESCO Asia and Pacific Regional Bureau for Education. Retrieved from http://unesdoc.unesco.org/images/0013/001355/135562e.pdf

Vernadakis, N. (2012). A comparison of student satisfaction between traditional and blended technology course offerings in physical education. Turkish Online Journal of Distance Education, 13(1).

Victori, M. \& Lockhart, W. (1995). Enhancing metacognition in self-directed language learning. System, 23(2), 223-234.

Wahit, F., \& Mohd, M. (2013). Evaluation on usability of enhancement e-learning of PTPL College Sabah with social networking elements. Paper presented at the 4th International Conference on Electrical Engineering and Informatics (ICEEI 2013). Retrieved from http://ac.els-cdn.com/S2212017313004532/1-s2.0-S2212017313004532main.pdf? tid=26a80572-9938-11e6-bd4d00000aacb361\&acdnat $=1477237892$ 2f8771b092a506d060cbb9a7b631a506

Wallace, A. (2014). Social learning platforms and the flipped classroom. International Journal of Information and Education Technology, 4(4), 293-296. doi:10.7763/ijiet.2014.v4.416

Walsham, G. (1993). Interpreting information systems in organizations. Chichester, NH: Wiley. 
Wang, T. P. (2007). The comparison of the difficulties between cooperative learning and traditional teaching methods in college English teachers. Journal of Human Resource and Adult Learning, 3(2).

Woo, Y., \& Reeves, T. C. (2007). Meaningful interaction in web-based learning: A social constructivist interpretation. Internet and Higher Education, 10, 15-25.

Woroniecka, I. (1998). A nonnative student's reactions to instructors' feedback on his papers: A case study of an undergraduate history student (Master's thesis). University of Toronto, Department of Curriculum, Teaching and Learning, Ontario Institute for Studies in Education of the University of Toronto. Retrieved from https://tspace.library.utoronto.ca/bitstream/1807/15210/1/MQ40680.pdf

Yin, R. K. (2011). Qualitative research: From start to finish. United States: The Guilford Press. 